\title{
Penerapan Metode Multi Factor Evaluation Process Pada Sistem Pendukung Keputusan Penentuan Kelayakan Pemberi Pinjaman (Studi Kasus NSC Finance Kota Lubuklinggau)
}

\author{
Andoko $^{1}$, Alfiarini ${ }^{2}$, Robi Yanto ${ }^{3}$ \\ ${ }^{1,2,3}$ STMIK Bina Nusantara Jaya Lubuklinggau \\ Jl. Yos Sudarso no. 97 A Kel. Jawa Kanan Telp. (0733) 322307 Fax (0733) 325306 \\ Jurusan Sistem Informasi, STMIK Bina Nusantara Jaya Lubuklinggau \\ 12andoko465@gmail.com, ${ }^{2}$ Alfiarini4@gmail.com, ${ }^{3}$ wrtch30@gmail.com
}

\begin{abstract}
PT. Nusa Surya Ciptadana (NSC) Finance is a company engaged in the formal retail of motorcycles, which provides one of the services of credit fund lenders. As one of the companies that provide credit fund lending services, NSC Finance faced the problem that is in determining the feasibility of the lender is still done manually. The Leader checks in detail against the files in hard copy and completeness of other requirements. This makes leadership difficult in making decisions. This is the basis of the authors to conduct research with the title Application of the method of Multi Factor Evaluation Process on Decision Support System Licensor Feasibility determination (case study NSC Finance in the city of Lubuklinggau). With the construction of a system is expected to assist leaders in decision support supporters
\end{abstract}

Keywords : SPK, MFEP, The creditworthiness of The Lender.

\begin{abstract}
Abstrak
PT. Nusa Surya Ciptadana (NSC) Finance merupakan perusahaan yang bergerak di bidang retail resmi sepeda motor, yang memberikan salah satu pelayanan yaitu pemberi dana pinjaman kredit. Sebagai salah satu perusahaan yang menyediakan pelayanan pemberi dana pinjaman kredit, NSC Finance dihadapkan permasalan yaitu dalam penentuan kelayakan pemberi pinjaman masih dikerjakan secara manual. Pimpinan memeriksa secara detail terhadap berkas-berkas dalam bentuk hard copy dan kelengkapan persyaratan lainnya. Hal ini membuat pimpinan kesulitan dalam pengambilan keputusan. Hal ini yang mendasari penulis untuk melakukan penelitian dengan judul Penerapan metode Multi Factor Evaluation Process pada Sistem Pendukung Keputusan Penentuan kelayakan Pemberi Pinjaman (studi kasus NSC Finance di kota Lubuklinggau).dengan dibangunnya sebuah sistem diharapkan dapat membantu pimpinan dalam pendukung pengambilan keputusan.
\end{abstract}

Kata kunci : SPK, MFEP, Kelayakan pemberi pinjaman.

\section{PENDAHULUAN}

PT. Nusa Surya Ciptadana (NSC Finance) merupakan perusahaan yang bergerak di bidang retail resmi sepeda motor, yang memberikan salah satu pelayanan yaitu pemberi pinjaman kredit. Sebagai salah satu perusahaan yang menyediakan pelayanan pemberi pinjaman kredit, NSC Finance dihadapkan permasalan yaitu adanya keputusan yang belum tepat oleh 
pimpinan karena dalam pengambilan keputusan pimpinan memberikan keputusan tanpa melakukan perhitungan terhadap alternatif sehingga mengakibatkan banyaknya konsumen yang menunggak pembayarannya serta dalam penentuan kelayakan pemberi pinjaman pimpinan memeriksa secara detail terhadap berkas-berkas dalam bentuk hard copy dan kelengkapan persyaratan lainnya sehingga membuat pimpinan kesulitan dalam pengambilan keputusan. Oleh karena itu dibutuhkan sebuah sistem pendukung keputusan untuk membantu dalam penentuan pemberi pinjaman. Agar dapat meminimalisir terjadinya kesalahan dalam proses pengambilan keputusan untuk penentuan pemberi pinjaman.

Dari permasalahan diatas, penulis menawarkan sebuah sistem pendukung keputusan dalam penentuan kelayakan pemberi pinjaman yang nantinya dapat membantu pengambilan keputusan. Hal ini yang mendasari penulis untuk melakukan penelitian dengan judul Penerapan metode Multi Factor Evaluation Process pada Sistem Pendukung Keputusan Penentuan Kelayakan Pemberi Pinjaman (studi kasus NSC Finance di kota Lubuklinggau).

\section{TINJAUAN PUSTAKA}

\subsection{Sistem Pendukung Keputusan}

Menurut Meri Azmi Dkk. (2014) yaitu suatu sistem informasi komputer yang interaktif yang dapat memberikan alternatif solusi bagi pengambil keputusan [2]. Menurut Rabiatul Adawiah dan Ruliah (2013) sistem pendukung keputusan (decision support system) merupakan suatu istilah yang mengacu pada suatu sistem yang memanfaatkan dukungan komputer dalam proses pengambilan keputusan [1].

\subsection{Peminjaman}

Menurut KBBI yaitu Pinjam - meminjam merupakan memakai barang (uang dan sebagainya) orang lain untuk waktu tertentu (kalau sudah sampai waktunya harus dikembalikan). Peminjaman atau pinjaman frasa dengan mempertahankan makna leksikal dan/atau makna gramatikal aslinya, tetapi dengan mengganti morfem dan fonemnya. Peminjaman atau pinjaman kata atau frasa dari bahasa lain dengan mengubah bentuk fonologinya sehingga dikira merupakan sumber asli [4].

\subsection{Kelayakan}

Menurut KBBI Kelakan merupakan prihal kepatutan, kepantasan dan prihal yang dapat dikerjakan. Berdasarkan pengertian diatas dapat disimpulkan bahwa kelayakan pemberian pinjaman merupakan kelayakan seseorang untuk menerima peminjaman (uang) [5].

\subsection{Jaminan Kredit}

Undang -Undang Republik Indonesia No 1 Tahun 2016 (Pasal 1) Penjaminan adalah kegiatan pemberian jaminan oleh Penjamin atas pemenuhan kewajiban finansial Terjamin kepada Penerima Jaminan [9].

\subsection{BPKP dan STNK}

POLRI Kepolisian Negara Republik Indonesia menyatakan bahwa BPKB merupakan Buku yang dikeluarkan atau diterbitkan oleh satuan lalu lintas polri sebagai bukti kepemilikan kendaraan bermotor. Sedangkan STNK merupakan surat tanda nomor kendaraan bermotor dan tanda nomor kendaraan bermotor. Fungsi BPKP dapat dijadikan sebagai Jaminan atau tanggungan dalam pinjam-meminjam berdasarkan kepercayaan masyarakat [6].

\subsection{Metode Multi Factor Evaluation Process}

Dalam jurnal Heny Pratiwi (2014) Render dan Stair (2002) menyatakan MFEP adalah metode kuantitatif yang menggunakan "weighting system" dalam pengambilan keputusan multi 
faktor, pengambilan keputusan secara subjektif dan intuitif menimbang berbagai faktor yang mempunyai pengaruh penting terhadap alternatif pilihan mereka [7].

Menurut Ferry Febrianto dkk (2016) langkah langkah dalam proses perhitungan MFEP [3], yaitu:

1) Menentukan faktor dan bobot faktor dimana total pembobotan harus sama dengan $1(\Sigma$ pembobotan =1), yaitu factor weight.

2) Mengisikan nilai untuk setiap faktor yang mempengaruhi dalam pengambilan keputusan dari data-data yang akan diproses, nilai yang dimasukkan dalam proses pengambilan keputusan merupakan nilai objektif.

3) Proses perhitungan weight evaluation yang merupakan proses perhitungan bobot antara factor weight dan factor evaluation dengan serta penjumlahan seluruh hasil weight evaluations untuk memperoleh total hasil evaluasi.

Penggunaan model MFEP dapat direalisasikan dengan rumus berikut:

$\mathrm{We}=\mathrm{w} * \mathrm{e}$

(1)

Keterangan:

$\mathrm{We}=$ Evaluasi Bobot

$\mathrm{W}=$ Bobot Kriteria

$\mathrm{e}=$ Evaluasi Sub Kriteria

$\mathrm{W}=\mathrm{W} 1+\mathrm{W} 2+\mathrm{W} 3+---+\mathrm{Wn}$

Keterangan:

$\mathrm{W}=$ Total Bobot Kriteria

$\mathrm{w}=$ Bobot Kriteria

4) Membandingkan nilai Total bobot kriteria antar alternatif kemudian mengurutkan berdasarkan nilai tertinggi.

\subsection{Metode Penelitian}

Menurut Rosa A.S dan M. Shalahudin (2013:28) Model SDLC air terjun (waterfall) sering juga disebut model sequensial linier (sequential linear) atau alur hidup klasik (clasik life cycle). Model air terjun menyediakan pendekatan alur hidup perangkat lunak secara sequensial atau berturut dimulai dari analisis, desain, pengkodean, pengujian, dan tahap pendukung (support). Berikut adalah model air terjun [8]:

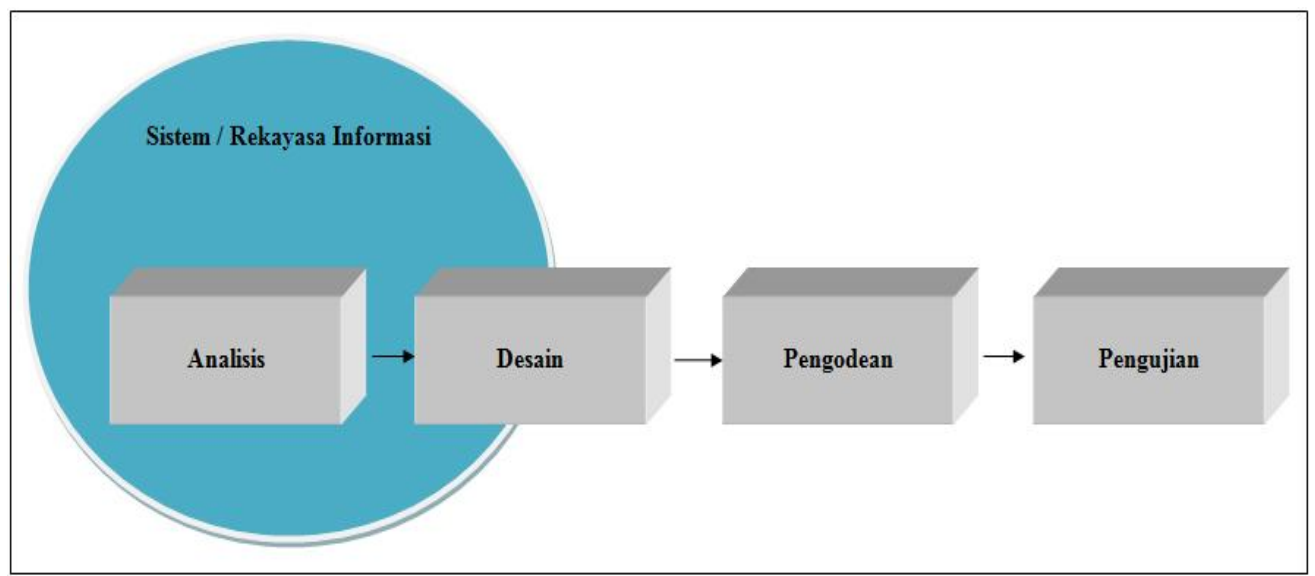

Sumber : Rossa A.S dan Salahuddin (2013:29)

Gambar 1. Model Waterfall 
Tahapan tahapan dalam model Waterfall :

1) Analisis kebutuhan perangkat lunak

Proses pengumpulan kebutuhan dilakukan secara intensif untuk menspesifikasikan kebutuhan perangkat lunak agar dapat dipahami perangkat lunak seperti apa yang dibutuhkan oleh user. Spesifikasi kebutuhan perangkat lunak pada tahap ini perlu untuk didokumentasikan.

2) Desain

Desain perangkat lunak adalah proses multi langkah yang fokus pada desain pembuatan program perangkat lunak termasuk struktur data, arsitektur perangkat lunak, representasi antar muka, dan prosedur pengodean. Tahap ini mentranslasi kebutuhan perangkat lunak dari tahap analisis kebutuhan ke representasi desain agar dapat diimplementasikan menjadi program pada tahap selanjutnya. Desain perangkat lunak yang dihasilkan pada tahap ini juga perlu didokumentasikan.

3) Pembuatan kode program

Desain harus ditranslasikan ke dalam program perangkat lunak. Hasil dari tahap ini adalah program komputer sesuai dengan desain yang telah dibuat pada tahap desain.

4) Pengujian

Pengujian fokus pada perangkat lunak secara dari segi logik dan fungsional dan memastikan bahwa semua bagian sudah diuji. Hal ini dilakukan untuk meminimalisir kesalahan (error) dan memastikan keluaran yang dihasilkan sesuai dengan yang diinginkan.

5) Pendukung (suport) atau pemeliharaan (maintenance)

Tidak menutup kemungkinan sebuah perangkat lunak mengalami perubahan ketika sudah dikirimkan ke user. Perubahan bisa terjadi karena adanya kesalahan yang muncul dan tidak terdeteksi saat pengujian atau perangkat lunak harus beradaptasi dengan linhkungan baru. Tahap pendukung atau pemeliharaan dapat mengualangi proses pengembangan mulai dari analisis spesifikasi untuk perubahan perangkat lunak yang sudah ada, tapi tidak untuk membuat perangkat lunak yang baru.

\subsection{Objek Penelitian}

Objek penelitian yang penulis ambil yaitu pada NSC Finance Kota Lubuklinggau

\subsection{Kebutuhan Data}

1) Pendataan Admin

Pendataan admin merupakan suatu halaman yang berisi tentang proses inputan data admin. Data admin ini akan digunakan untuk proses login, dimana hanya pengguna yang memiliki hak akses.

2) Pendataan Nasabah

Pendataan nasabah merupakan suatu halaman yang berisi tentang proses inputan data nasabah.

3) Pendataan Faktor

Pendataan faktor merupakan suatu halaman yang berisi tentang proses inputan data faktor.

4) Pendataan Sub Faktor

Pendataan sub faktor merupakan suatu halaman yang berisi tentang proses inputan data sub faktor.

5) Pendataan Penilaian

Pendataan penilaian merupakan suatu halaman yang berisi tentang proses perhitungan dalam penentuan kelayakan penerima peminjaman.

\subsection{Metode Pengumpulan Data}

1) Interview

interview atau lebih sering disebut wawancara merupakan teknik pengumpulan data yang dilakukan secara langsung dengan kepala bagian Marketing di NSC Finance Kota 
Lubuklinggau untuk mendapatkan informasi mengenai sistem kelayakan pemberi pinjaman dan mendapatkan data yang berkaitan dengan hal tersebut.

2) Observasi

Merupakan kegiatan pengamatan secara langsung untuk mengamati proses dalam penentuan kelayakan pemberi pinjaman yang berfokus pada bagaimana sistem pendukung keputusan untuk kelayakan penerima pinjaman sampai penentuan penerima yang layak terpilih sebagai penerima.

3) Study leteratur

Teknik pengumpulan data yang diperoleh dari berbagai literatur-literatur, buku terbitan dan publikasi mengenai pembahasan.

\section{RANCANG BANGUN SISTEM}

\subsection{Analisis Prosedur Kerja}

Dalam tahapan pengambilan keputusan untuk pemberian pinjaman pada NSC Finance dinilai melalui 5 (Lima) kategori atau kriteria yang telah ditetapkan yaitu kelengkapan berkas, jumlah penghasilan, pekerjaan, tahun motor dan jumlah tanggungan. Dalam pengajuan pinjaman nasabah mengajukan permohonan pinjaman lalu sales lapangan akan melakukan survey lapangan ke tempat melakukan wawancara untuk mendapatkan data yang dibutuhkan. Setelah itu PIC Marketing menerima berkas atau laporan dari tim sales lapangan berupa data laporan pengajuan peminjaman yang dalam bentuk hard copy lalu dilakukan pengecekan ulang terhadap berkas tersebut berdasarkan 5 (lima) kriteria yang telah ditetapkan dan PIC Marketing akan memberikan keputusan apakah pengaju pinjaman diterima atau ditolak.

\subsection{Analisis Pemecahan Masalah}

1) Analisis

Dalam proses pemberian dana pinjaman terdapat permasalahan yaitu belum tepatnya keputusan yang diambil pimpinan sehingga setelah diterima banyak nasabah menunggak atau macet dalam proses pembayarannya serta dalam penentuan kelayakan pemberi pinjaman masih dikerjakan secara manual. Pimpinan memeriksa secara detail terhadap berkas-berkas dalam bentuk hard copy dan kelengkapan persyaratan lainnya. Hal ini membuat pimpinan kesulitan dalam pengambilan keputusan. Untuk itu peneliti memberikan solusi terhadap masalah yang tengah dihadapi NSC Finance yaitu dengan membangun sebuah sistem pendukung keputusan untuk penentuan kelayakan pemberi pinjaman pada NSC Finance.

2) Sitem Pendukung Keputusan

Dalam pengambilan keputusan agar data dapat diperhitungkan berdasarkan kriteria yang sudah ada peneliti menggnakan metode perhitungan Multi Factor Evaluation Process (MFEP) untuk mencari nilai tertinggi dan menjadi pendukung keputusan yang akan diambil oleh pimpinan kepala cabang.

\subsection{Perhitungan dengan Multi Factor Evaluation Process}

1) menentukan faktor beserta sub faktor dan bobot

Tabel 1. Bobot Factor

\begin{tabular}{|c|c|l|c|}
\hline No & Insial & \multicolumn{1}{|c|}{ Faktor } & Bobot \\
\hline 1 & A & Kelengkapan Berkas & 0,35 \\
\hline 2 & B & Penghasilan & 0,25 \\
\hline 3 & C & Pekerjaan & 0,20 \\
\hline 4 & D & Tahun Motor & 0,10 \\
\hline 5 & E & Jumlah Tanggungan & 0,10 \\
\hline \multicolumn{2}{|c|}{ Jumlah } & 1 \\
\hline
\end{tabular}


Tabel 2. Bobot Sub Faktor Kelengkapan Berkas

\begin{tabular}{|c|l|c|}
\hline No & Sub Faktor & Bobot \\
\hline 1 & lengkap & 0,75 \\
\hline 2 & tidak lengkap & 0,25 \\
\hline \multicolumn{2}{|c|}{ Jumlah } & 1 \\
\hline
\end{tabular}

Tabel 3. Bobot Sub Faktor Penghasilan

\begin{tabular}{|c|c|c|}
\hline No & Sub Faktor & Bobot \\
\hline 1 & Penghasilan $\leq 1.000 .000$ & 0,02 \\
\hline 2 & $1.000 .000<$ Penghasilan $\leq 2.000 .000$ & 0,03 \\
\hline 3 & $2.000 .000<$ Penghasilan $\leq 3.000 .000$ & 0,04 \\
\hline 4 & $3.000 .000<$ Penghasilan $\leq 4.000 .000$ & 0,05 \\
\hline 5 & $4.000 .000<$ Penghasilan $\leq 5.000 .000$ & 0,06 \\
\hline 6 & $5.000 .000<$ Prnghasilan $\leq 6.000 .000$ & 0,08 \\
\hline 7 & $6.000 .000<$ Penghasilan $\leq 7.000 .000$ & 0,12 \\
\hline 8 & $7.000 .000<$ Penghasilan $\leq 8.000 .000$ & 0,15 \\
\hline 9 & $8.000 .000<$ Penghasilan $\leq 9.000 .000$ & 0,20 \\
\hline 10 & $9.000 .000<$ Penghasilan & 0,25 \\
\hline \multicolumn{2}{|c|}{ Jumlah } & 1 \\
\hline
\end{tabular}

Tabel 4. Bobot Sub Faktor Pekerjaan

\begin{tabular}{|c|l|c|}
\hline No & \multicolumn{1}{|c|}{ Sub Faktor } & Bobot \\
\hline 1 & Tidak Bekerja & 0,03 \\
\hline 2 & Serabutan & 0,07 \\
\hline 3 & Petani & 0,15 \\
\hline 4 & Wirausaha & 0,20 \\
\hline 5 & Karyawan & 0,25 \\
\hline 6 & Pns Jumlah & 0,30 \\
\hline \multicolumn{2}{|c|}{} & 1 \\
\hline
\end{tabular}

Tabel 5. Bobot Sub Faktor Tahun Motor

\begin{tabular}{|c|c|c|}
\hline No & Sub Faktor & Bobot \\
\hline 1 & 2010 & 0,03 \\
\hline 2 & 2011 & 0,07 \\
\hline 3 & 2012 & 0,10 \\
\hline 4 & 2013 & 0,12 \\
\hline 5 & 2014 & 0,18 \\
\hline 6 & 2015 & 0,20 \\
\hline 7 & $2016 \quad$ Jumlah & 0,30 \\
\hline \multicolumn{2}{|c|}{} & 1 \\
\hline
\end{tabular}

Tabel 6. Bobot Sub Faktor Tanggungan

\begin{tabular}{|c|l|c|}
\hline No & Sub Faktor & Bobot \\
\hline 1 & 1 & 0,30 \\
\hline 2 & 2 & 0,25 \\
\hline 3 & 3 & 0,20 \\
\hline 4 & 4 & 0,15 \\
\hline 5 & $5<$ Jumlah Tanggungan & 0,10 \\
\hline \multicolumn{2}{|c|}{ Jumlah } & 1 \\
\hline
\end{tabular}


2) Mengisikan nilai alternatif pada tiap faktor yang diperlukan dalam proses pengambilan keputusan, nilai yang dimasukkan merupakan nilai subjektif yaitu faktor evaluation yang nilainya $0-1$

Tabel 7. Nilai Alternatif

\begin{tabular}{|c|l|c|c|c|c|c|}
\hline \multirow{2}{*}{ No } & \multicolumn{1}{|c|}{ Faktor } & A & B & C & D & E \\
\cline { 2 - 7 } & \multicolumn{1}{|c|}{ Bobot } & $\mathbf{0 , 3 5}$ & $\mathbf{0 , 2 5}$ & $\mathbf{0 , 2 0}$ & $\mathbf{0 , 1 0}$ & $\mathbf{0 , 1 0}$ \\
\hline 1 & Bambang Irawan & 0.75 & 0.04 & 0.07 & 0.10 & 0.20 \\
\hline 2 & Bunaya & 0.75 & 0.04 & 0.15 & 0.10 & 0.20 \\
\hline 3 & Maiyani & 0.75 & 0.05 & 0.25 & 0.12 & 0.25 \\
\hline 4 & Murni & 0.75 & 0.08 & 0.25 & 0.10 & 0.20 \\
\hline 5 & Latif & 0.75 & 0.06 & 0.30 & 0.15 & 0.20 \\
\hline
\end{tabular}

3) Proses perhitungan weight evaluation merupakan perhitungan antara faktor weight dan faktor evaluation dengan penjumlahan, dari hasil weight evaluation dapat menentukan hasil evaluasi

a) Weight Kelengkapan Berkas

$\mathrm{We}=\mathrm{W} * \mathrm{e}$

W (Bambang Irawan)

$=0,75 * 0,35=0.26$

W (Bunaya)

$=0,75 * 0,35=0.26$

W (Maiyani)

$=0,75 * 0,35=0.26$

W (Murni)

$=0,75 * 0,35=0.26$

W (Latif)

$=0,75 * 0,35=0.26$

b) Weight Penghasilan

W (Bambang Irawan)

$=0,04 * 0,25=0.01$

W (Bunaya)

W (Maiyani)

W (Murni)

W (Latif)

$=0,04 * 0,25=0.01$

$=0,05 * 0,25=0,12$

$=0,08 * 0,25=0.02$

$=0,06 * 0,25=0.15$

c) Weight Pekerjaan

W (Bambang Irawan)

$=0,07 * 0,20=0.01$

W (Bunaya)

$=0,15 * 0,20=0.03$

W (Maiyani)

$=0,25 * 0,20=0,05$

W (Murni)

$=0,25 * 0,20=0.05$

W (Latif)

$=0,30 * 0,20=0.06$

d) Weight Tahun Motor

W (Bambang Irawan)

$=0,10 * 0,10=0.01$

W (Bunaya)

W (Maiyani)

W (Murni)

$=0,10 * 0,10=0.01$

$=0,12 * 0,10=0,12$

$=0,10 * 0,10=0.10$

W (Latif)

$=0,15 * 0,10=0.15$

e) Weight Tanggungan

W (Bambang Irawan)

W (Bunaya)

$=0,20 * 0,10=0.02$

W (Maiyani)

$=0,20 * 0,10=0.02$

W (Murni)

$=0,25 * 0,10=0,025$

W (Latif)

$=0,20 * 0,10=0.02$

$=0,20 * 0,10=0.02$ 
Tabel 8. Nilai Weight Evaluation

\begin{tabular}{|c|l|c|c|c|c|c|}
\hline No & \multicolumn{1}{|c|}{ Faktor } & A & B & C & D & E \\
\hline 1 & Bambang Irawan & 0.26 & 0.01 & 0.01 & 0.01 & 0.02 \\
\hline 2 & Bunaya & 0.26 & 0.01 & 0.03 & 0.01 & 0.02 \\
\hline 3 & Maiyani & 0.26 & 0.012 & 0.05 & 0.012 & 0.025 \\
\hline 4 & Murni & 0.26 & 0.02 & 0.05 & 0.01 & 0.02 \\
\hline 5 & Latif & 0.26 & 0.015 & 0.06 & 0.015 & 0.02 \\
\hline
\end{tabular}

4) Menjumlahkan seluruh hasil weight evaluation untuk memperoleh total hasil evaluasi. $\mathrm{W}=\mathrm{w} 1+\mathrm{w} 2 \ldots \ldots \mathrm{wn}$

$$
\begin{array}{ll}
\mathrm{W} \text { (Bambang Irawan) } & =0,26+0,01+0,01+0,01+0,02=0,31 \\
\mathrm{~W} \text { (Bunaya) } & =0,26+0,01+0,03+0,01+0,02=0,33 \\
\mathrm{~W} \text { (Maiyani) } & =0,26+0,012+0,05+0,012+0,025=0,36 \\
\mathrm{~W} \text { (Murni) } & =0,26+0,02+0,05+0,01+0,02=0,36 \\
\mathrm{~W} \text { (Latif) } & =0,26+0,01+0,06+0,015+0,02=0,37
\end{array}
$$

Tabel 9. Total Hasil Evaluasi

\begin{tabular}{|c|l|c|c|c|c|c|c|}
\hline No & \multicolumn{1}{|c|}{ Faktor } & A & B & C & D & E & Jumlah \\
\hline 1 & Bambang Irawan & 0.26 & 0.01 & 0.01 & 0.01 & 0.02 & 0,31 \\
\hline 2 & Bunaya & 0.26 & 0.01 & 0.03 & 0.01 & 0.02 & 0,33 \\
\hline 3 & Maiyani & 0.26 & 0.012 & 0.05 & 0.012 & 0.025 & 0,36 \\
\hline 4 & Murni & 0.26 & 0.02 & 0.05 & 0.01 & 0.02 & 0,36 \\
\hline 5 & Latif & 0.26 & 0.015 & 0.06 & 0.015 & 0.02 & 0,37 \\
\hline
\end{tabular}

Berdasarkan tabel 3.9 diatas, dapat dilihat bahwa nasabah yang dapat dikatakan layak sebagai penerima pinjaman adalan Latif dengan hasil nilai 0,37.

\section{HASIL}

\subsection{Halaman Proses}

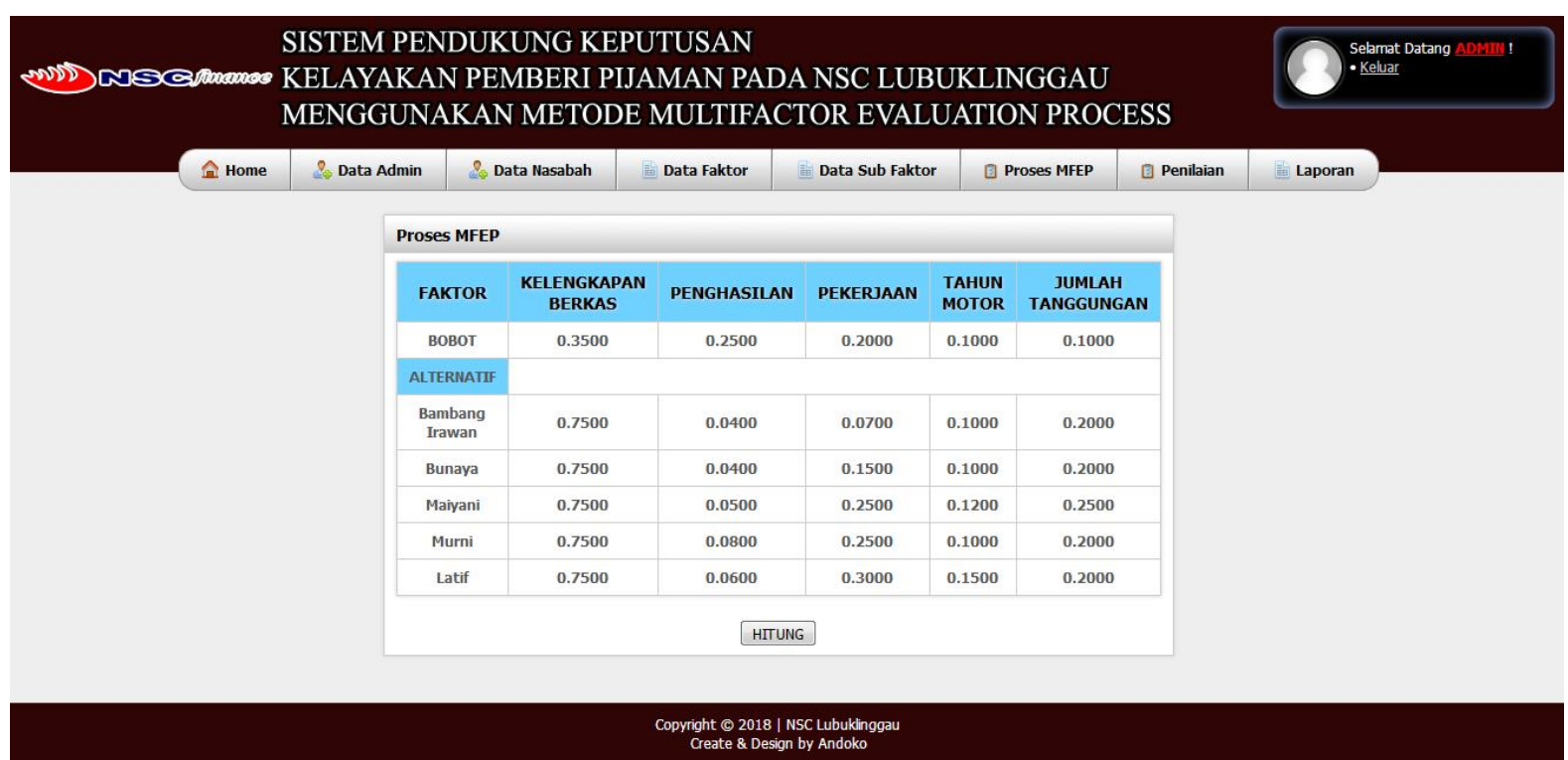

Gambar 2. Halaman Proses 
Merupakan proses perhitungan dengan seluruh jumlah nasabah yang telah di input sebelumnya lalu dilakukan perhitungan dengan mengklik Hitung dan akan masuk pada halaman penilaian. Tampilan halaman proses perhitungan dapat dilihat pada gambar 4.1

\subsection{Halaman Penilaian}

3. Total Hasil Evaluasi

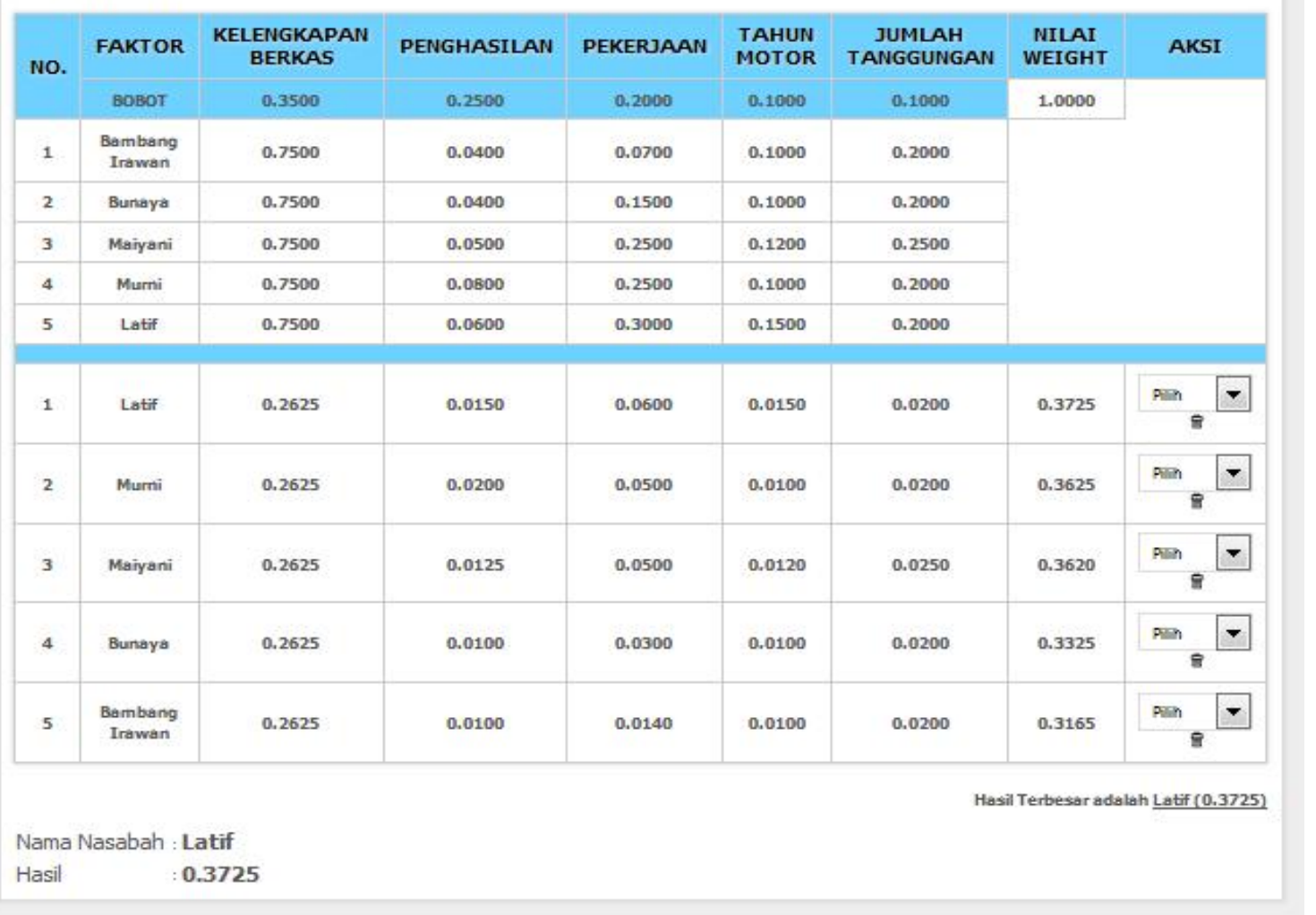

Gambar 3. Halaman Penilaian

Halaman penilaian ini berfungsi untuk menampilkan hasil dari proses perhitungan dengan menampilkan data nasabah berdasarkan hasil terbesar dengan hasil terbesar merupakan salah satu pendukung dalam pengambilan keputusan sebagai nasabah yang akan menerima pinjaman. Tampilan halaman penilaian ini dapat dilihat pada gambar 4.2.

\section{KESIMPULAN}

1) Menghasilkan suatu sistem pendukung keputusan penentuan kelayakan pemberi pinjaman pada NSC Finance Lubuklinggau.

2) Sistem pendukung keputusan yang dibangun dapat dijadikan sebagai media pendukung dalam pengambilan keputusan untuk penentuan kelayakan pemberian pinjaman pada NSC Finance berdasarkan hasil tertinggi dengan perhitungan metode Multi Factor Evaluation Process. 


\section{SARAN}

1) Diharapkan pengembangan selanjutnya sistem dapat dikembangkan dengan berbasisis client server.

2) Untuk pengembangan selanjutnya sistem penentuan kelayakan pemberi pinjaman dapat dilakukan secara online agar karyawan juga dapat melihat dan memprediksikan nasabah yang melakukan pengajuan dana.

\section{UCAPAN TERIMA KASIH}

Ucapan terimakasi ini penulis tujukan kepada dosen pembimbing penulis Bapak Robi Yanto, M.Kom dan Ibu Alfiarini, S.Kom,, M.M. yang telah membimbing penulis selama penelitian yang telah memberikan arahan yang terbaik.

\section{DAFTAR PUSTAKA}

[1] Adawiah, Rabiatul., dan Ruliah., 2013, Sistem Pendukung Keputusan Pemilihan Penerima Beasiswa Berbasis Fuzzy Mamdani, Volume.9, No.1, ISSN: 0216-3284. Halaman 899-906.

[2] Azmi, Meri., Sonatha, Yance., dan Rasydah., 2014, Pemanfaatan Sistem Pendukung Keputusan Untuk Penentuan Alokasi Dana Kegiatan (Studi Kasus Unit Kegiatan Mahasiswa Politeknik Negeri Padang), Jurnal Momentum, Volume.16, No.1, ISSN: 1693752X. Halaman 74-83.

[3] Febrianto, Ferri., Agus, Fahrul dan Kridalaksana, Awang, Harsa., 2016, Sistem Pendukung Keputusan Pemilihan Sepeda Menggunakan Metode Multi Factor Evaluation Process, Prosiding Seminar Ilmu Komputer dan Teknologi Informasi, Volume.1, No.1, ISSN: 25407902. Halaman 17-23.

[4] Kamus Besar Bahasa Indonesia (KBBI), 2017, Pengertian Pinjaman, (Online), https://www.kbbi.web.id/pinjam, Diakses 16 November 2017.

[5] Kamus Besar Bahasa Indonesia (KBBI), 2017, Pengertian Layak, (Online), https://kbbi.web.id/laik, Diakses 19 Desember 2017.

[6] Kepolisian Negara Republik Indonesia, Tentang BPKB dan STNK, (Online), www.polri.go.id Diakses 19 Desember 2017.

[7] Pratiwi, Henry., 2014, Sistem Pendukung Keputusan Penentuan Karyawan Berprestasi Menggunakan Metode Multi Factor Evaluation Process, Jurnal Sistem Informasi, Volume.5, No.2, Halaman 95-101.

[8] Rossa, A.S., M.Shalahuddin. 2013, Rekayasa Perangkat Lunak, Informatika Bandung, Bandung.

[9] Undang-Undang Republik Indonesia Nomor 1 Tahun 2016, Tentang Penjaminan, (Online), http://politeia.id/files/dokumen/DI1284UU_NO_1_2016\%20tentang\%20Penjaminan.pdf, Diakses 14 November 2017. 